\title{
EDUCATIONAL PSYCHOLOGY
}

\section{Psychological resources of modern Russian adolescents' resilience to violence in the educational environment}

\author{
Irina A. Baeva ${ }^{\mathrm{a}^{*}}$, Yury P. Zinchenko ${ }^{\mathrm{b}}$, Vladimir V. Laptev ${ }^{\mathrm{c}}$ \\ ${ }^{a}$ Department of Educational and Development Psychology, Herzen State Pedagogical University \\ of Russia, St. Petersburg, Russia \\ ${ }^{\mathrm{b}}$ Faculty of Psychology, Lomonosov Moscow State University, Moscow, Russia \\ ${ }^{c}$ Herzen State Pedagogical University of Russia, St. Petersburg, Russia \\ *Corresponding author. E-mail: irinabaeva@mail.ru
}

Determination of the personality's psychological resources that ensure its resilience to negative effects of the social environment is a priority problem in modern society, science, and education, since we currently see a sharp increase in the number of factors that affect psychological hardiness and security. One of these is intensification of violent and aggressive forms of interaction in educational institutions. Such manifestations are especially dangerous in schools, since, by virtue of their age-specific features, students are the most vulnerable and they subsequently translate the acquired values and behaviors to society as a whole. The goal of this empirical study was to identify teenagers' psychological resources that determine their resilience to various forms of psychological violence in the educational environment. The study covered four St. Petersburg high schools, with 437 teenagers aged from 16.5 to 17 (189 boys and 248 girls). A questionnaire was developed to divide the subjects into groups with high and low levels of protection (security) against psychological violence in the educational environment. The questionnaire lists forms of psychological violence in the educational environment (identified by theoretical review) that can occur in interpersonal communication between peers and between teachers and students. The respondents evaluated each item of the questionnaire in accordance with the proposed scale of frequency with which each form of violence occurred. Theoretical analysis determined that psychological violence is traumatic for the adolescent personality's cognitive, emotional, and behavioral spheres. The teenagers' psychological resources of resilience to violence in the educational environment were identified with the aid of psychodiagnostic methods addressing each of them. Our study allows us to conclude that the resources that ensure the teenager's resilience to the negative effect of psychological violence in the educational environment are: satisfaction with oneself, accepting oneself as a personality with positive and socially desirable characteristics; high level of 
self-control, well- developed ability to behave in an acceptable way whatever the circumstances; openness and goodwill, self-confidence; perception of the surrounding world as friendly and generous, which gives rise to friendly behavior; holistic perception of the world, experiencing the present moment in one's life in its entirety, striving for personal development and self-improvement; independence of values and behavior from external factors; significance of such values as achievement, self-development, and high financial position, in combination with a priority on learning and education; explanation as a typical mechanism of psychological protection, search for a reasonable basis for justifying behavior and actions as well as impulsive acts; low level of anxiety, aggressiveness, and rigidity. The results obtained can be useful for researching the resource-oriented approach to psychology, and also for the development of follow-up techniques for ensuring the safety of the educational environment, preventing all forms of violence in interpersonal interaction between students and teachers.

Keywords: psychological resources, resilience of the individual, psychological violence, educational environment

\section{Introduction}

The study of human resilience to negative effects of the social environment a promising area of modern research. The current interest in this problem is sparked by the ongoing radical social, political, and economic changes in the country (Russia), which affect every sphere of social life, changing the socio-cultural situation as a whole, and sometimes leading to greater social tension and conflict, and more violence in all social systems, including the educational system. Acts of violence against a single person, a group of people, or large communities necessitate a search for resources to promote hardiness and resilience, and identification of people's internal capacities that can ensure their psychological security.

Amid abrupt changes in social and economic life, we find such phenomena as higher mental workload, changes in the values and stereotypes of consciousness, and an increase in violent and aggressive forms of interaction in various social institutions. Such manifestations are especially dangerous in schools, since, by virtue of their age-specific features, students are the most vulnerable and they translate the acquired values, stereotypes, and forms of behavior to society as a whole. The fight against terrorism, which has become the greatest menace today, primarily uses military, economic, and political methods, but of no less importance is an educational system that could efficiently solve prevention, educational and prognostic problems. Reduction of violence in interpersonal interaction in the educational environment promotes the translation of the values of safety and nonviolence to social life.

Violence is traditionally understood as physical or sexual abuse; however, psychological pressure on the individual's personality, infringement of a person's rights and interests, limitation of one's needs and opportunities should also be regarded as acts of violence which, since they are widespread and often not perceived as such, may constitute the greatest danger to personality development. This type of violence is known as psychological or emotional.

In adolescence, unfavorable effects of the social environment are primarily manifested in problems with interpersonal communication and delay in the for- 
mation of new personality traits that are normal for this particular age. In many cases the factors that provoke this deformation are varied forms of psychological violence.

Theoretical concepts of violence are distinguished by a great variety of methodological approaches, yet the problem of psychological violence and its consequences for a person's effective functioning remains the least studied. There are virtually no publications that bring to light the individual's internal resources for countering and coping with mentally damaging consequences of psychological violence. There are several reasons for this.

First of all, it was only recently that the consequences of such violence were recognized and there is still no single definition of psychological violence. Secondly, many researchers face problems trying to diagnose it, because it can be durable but nevertheless not recognized by the victim, who may not realize that he or she has been exposed to such violence. Moreover, the initiator of violent actions does not necessarily perceive them as such. In addition, the consequences of psychological violence most often manifest themselves many years later, in the form of deformation of personality traits and behavioral reactions.

Most specialist publications on psychological problems of violence are devoted to violence against the child in the family or in the child's immediate social environment (Alekseeva, 2006; Alekseeva \& Novoselskii, 2005; Zinoveva \& Mikhailova, 2003). The problems of violence and measures for protecting children left without parental custody and children in the social orphanhood ${ }^{1}$ risk group have been widely discussed (Dubrovina, 2000). However, in present-day reality, children and teenagers are more and more frequently themselves the perpetrators of violence against their peers and adults, while teachers and other adults working with children commit (consciously and unconsciously) acts of violence against children. A considerable share of such acts of violence occurs in the educational environment. And while physical, and even more so sexual, violence is condemned morally and prosecuted legally, various forms of psychological violence remain outside the scope of public awareness or researchers' interests.

Researchers state that in Russia there is no uniform approach to defining such terms as violence and cruel treatment, not to mention abuse, coercion, exploitation, and battered child syndrome. In most cases people tend to regard as violence only an insignificant part of the events that damage human health and view it as falling within the purview of criminal law. Volkova (2001), generalizing the findings in the area of problems of violence and cruel treatment of children, formulates appropriate basic definitions. Violence includes all forms of physical and/or emotional cruelty; sexual violence; disregard or disdain; commercial or any other exploitation that leads to real or potential damage to the child's health, life, development, or dignity in the context of responsibility, and trust. Psychological violence means constantly repeated acts of humiliation, terrorization (threats, exposure to danger), or insults. Psychological violence is often described as emotional violence and verbal violence. Emotional and verbal violence are characterized by giving derogatory nicknames, insults, threats of physical violence or harm, shouting and manifesta-

1 Social orphans are children who had one or both biological parents alive but who were left without parental care and support, or abandoned. 
tions of anger, refusal to enter into a relationship (emotional and verbal isolation), pressure or coercion to do what the person does not want to do (Volkova, 2011, pp. 25-26).

In Russian psychological research, the problem of violence and aggressive behavior in schools has been little studied. A few studies touch upon development and support for schoolchildren's personality resources that ensure resilience to the negative effect of violence in the educational environment (Baeva, 2014; Volkova, 2011). Research into psychological problems of resilience focuses on ways of overcoming the adverse effects arising in the process of interaction between an individual's personality traits and unfavorable factors of the social environment.

Resilience research developed from studies of susceptibility to the destructive effect of the environment, such as problems with interpersonal relationships, family problems, or biological problems; then it focused on the factors and processes conducive to the formation of resilience to problems in those areas. The early studies already noted that biological risk factors can be corrected by environmental factors, and that individual characteristics can weaken the effect of unfavorable environmental conditions. Such characteristics include an easy-going temperament and the ability to find support outside the family (Davey, Eaker, \& Walters, 2003).

Originally the researchers' efforts were mostly aimed at understanding the pathology thought to be related to the lack of certain qualities or resources, rather than analysis of how the problems were resolved or prevented. The psychoanalytical point of view and the biomedical model, oriented towards identifying the source of pathology in the individual, were dominant in the studies of mental health. However it gradually became clear that such an approach has very limited application. Therefore, unlike studies of mental disorders as consequences of exposure to unfavorable environmental factors, studies of resilience do not focus on risk factors or negative consequences (e.g., illness), but emphasize protective factors instead. The tradition of resilience studies, even though its origin was interest in psychopathology, nevertheless offers an alternative to the deficit-based approach to the study of development under unfavorable conditions (Lam \& McBride-Chang, 2007).

As of today, in psychology there is no unambiguous interpretation or definition of resilience, which is defined as a mental process, personality trait, or mental state. Besides resilience, there are other constructs related to "invulnerability" under exposure to risk; the most widespread among them, according to international publications, are hardiness (Kobasa, Maddi, \& Kahn, 1982) and coping (Davey, Eaker, Walters, \& Matheny, 2003).

Russian studies consider the problem of resilience in the face of unfavorable social environment factors in line with the concept of psychological safety (Baeva, 2014; Zinchenko \& Zotova, 2010). Within this framework, the researchers have accumulated ample material related to the human psyche's functioning mechanisms in health-threatening circumstances. The researchers have mainly focused on identifying the personality features that can ensure optimum ways of confronting life's problems. Definitions have been proposed for psychological safety of the individual, such as the ability to "maintain stability in an environment with definite parameters, including exposure to psychotraumatic situations, resilience to destructive internal and external actions reflected in experiencing one's security/insecurity in 
a specific situation" (Baeva, Volkova, \& Laktionova, 2011, p. 125). The question is posed as to which personality features are the resources that ensure psychological well-being in various life circumstances.

Thus the urgency of studying the teenager's psychological resources that ensure his resilience to violence is conditioned not only by the acuteness of this social problem, but also by the significant contradictions in our conceptions of the nature of psychological violence, man's protective potential for opposing its negative consequences, as well as specific features of these phenomena in the educational environment. Moreover, the effect of psychological violence on personality formation and development has been insufficiently studied.

The goal of this study was to identify teenagers' psychological resources that determine their resilience to various forms of psychological violence in the educational environment.

\section{Method}

The study was conducted in four St. Petersburg schools. It involved 437 high school students, including 189 boys and 248 girls aged from 16.5 to 17 years.

To divide the subjects into groups according to high/low levels of resistance to psychological violence in the educational environment, a questionnaire (Psychological Violence in the Educational Environment) was developed, which was tested for content and construct validity.

The questionnaire is a list of manifestations of psychological violence (identified by theoretical review) that can occur in interpersonal communication both among peers and in the teacher-student communication in the educational environment. Each questionnaire comprises 20 items. Examples of peer violence included such items as: "Peers have ignored you for a long time"; "Peers have forced you to do something by threats"; "Peers have humiliated and ridiculed you". Examples of teacher violence were: "A teacher has made you feel that he thinks you're a fool if you don't understand something"; "A teacher has pretended not to notice you"; "A teacher has insulted you and made rude comments about your personality".

Each item was evaluated by the respondents on a four-point ordinal scale according to the frequency of occurrence of the given form of violence.

Data processing was performed by calculating the average score across all forms of psychological violence on the part of students and teachers. The integrative indicator of psychological abuse was calculated by summing up the scores on the two positions and was the basis for the division of the respondents into groups.

Several psychodiagnostic instruments were used to identify the psychological resources of teenage resilience to violence in the educational environment:

- to evaluate resistance to negative environmental factors: D.A. Leontiev's adaptation of S. Maddi's Hardiness Test (Leontiev, 2013);

- to identify psychological characteristics of the cognitive sphere: Personal Semantic Differential (Luchshie psikhologicheskie testi, 1992); Self-Actualization Test; Terminal Values Questionnaire designed by I. Senin (Karelin, 2007); 
- to identify psychological characteristics in the behavioral sphere: PlutchikKellerman-Conte's Life Style Index (Karelin, 2007);

- to identify psychological characteristics of the emotional sphere: Eysenck's Self-Appraisals of Mental States Questionnaire (Burlachuk \& Morozov, 2002).

D.A. Leontiev's adaptation of S. Maddi's Hardiness Test. This instrument reveals the intensity of resilience, understood as an integrative personality structure which is closely linked to success in overcoming difficult situations and to the interaction of an individual with unfavorable conditions as a factor that buffers their detrimental effect. As a personality variable, hardiness characterizes an individual's ability to withstand anxiety arising in difficult situations, while maintaining internal balance and performance level.

The instrument measures the overall level of resilience, which is positively correlated with the set of favorable outcomes, such as good physical health, academic success, ability to withstand professional burnout, etc.

In addition, the methodology makes it possible to identify individual components of resilience: commitment, control, and accepting risks.

Commitment is defined as a tendency to involve oneself in all kinds of activities and have a genuine interest in the surrounding world; it also implies the search for meaning and commitment to one's own life goals. Control is a tendency to believe and act as if one can influence the events taking place around oneself through one's own efforts. Accepting risks (or challenges) is defined as the ability to learn from experience, be it positive or not, considering it as a factor motivating personal growth in new circumstances.

Personal Semantic Differential (PD) was developed on the basis of the modern Russian language and reflects our culture's ideas about personality structure. It is aimed at creating a compact and valid tool for studying certain personality traits, self-awareness, and interpersonal relationships, which could be applied in clinical psychological and psychodiagnostic work, as well as in socio-psychological practice.

The PD is formed by a representative sample of words of the modern Russian language describing personality traits, followed by the study of internal factor structure, a kind of "model personality" that exists in the culture and is internalized by each person through the assimilation of social and linguistic experience.

One hundred and twenty words for personality traits were selected from a dictionary of the Russian language. After that, 21 personality descriptors were chosen from this initial set that best characterized the poles of the three classical bipolar pairs of semantic differential: 1) evaluation; 2) potency; and 3) activity.

In the study of self-appraisals, the factor of Evaluation (E) indicates the level of self-esteem; the potency factor $(\mathrm{P})$ indicates the development of volitional aspects of the personality as they are understood by the subject; the activity factor (A) is interpreted as evidence of an extroverted personality.

The Self-Actualization Test was developed on the basis of E. Shostrom's Personal Orientation Inventory (POI). POI scales were derived from A. Maslow's theory of self-actualization, and the ideas of F. Pearl and other theorists of existential and humanistic psychology. The test consists of 126 items, each including two judgments 
concerning values or behavior. The subject is asked to choose a judgment that most corresponds to his ideas or habitual behavior. The test measures self-actualization on two basic scales and several subscales. The basic scales are: the scale of time competence (TC) and scale of identification support (I). Twelve additional scales are divided into 6 units, each containing two scales:

1. The Self-Actualizing Value (SAV) and Existentiality (Ex) scales complement each other to form the unit of values. The first scale describes the values themselves, the second measures the lability of behavior.

2. The Feeling Reactivity (Fr) and Spontaneity (S) scales constitute the unit of feelings. The first scale measures the subjects' awareness of their own feelings, while the second determines the extent to which these are manifested in their behavior.

3. The Self-Regard (Sr) and the Self-Acceptance (Sa) scales form the unit of self-perception.

4. The Nature of Man-Constructive (Nc) and Synergy (Sy) scales constitute the unit of concepts about human nature.

5. The Acceptance of Aggression (A) and Capacity for Intimate Contact (C) scales constitute the unit of interpersonal sensitivity.

6. The Cognitive Needs (Cog) and Creativity (Cr) scales combine to form the unit of attitudes towards cognition.

The Terminal Values Questionnaire, developed by I. Senin, is based on M. Rokich's theoretical ideas about the structure of human values. It aims to diagnose personal life values.

The questionnaire consists of 80 statements, each to be evaluated by respondents on a 5 -point scale (irrelevant -1 , of small value -2 , of some value -3 , important -4 , very important -5$)$. The results are presented in the form of individual profiles, separately for the scales of life values ( 8 values) and life spheres (5 spheres).

The data obtained help to assess both the overall intensity of each of the eight life values, and its representation in various spheres of human life.

The eight life values are:

1. Prestige - gaining recognition by following certain social requirements;

2. High financial position - regarding material prosperity as the primary purpose in life;

3. Creativity - realization of one's own creative potential, desire to change the environment;

4. Active social contacts - establishing favorable relationships in various domains of social interaction, expanding one's interpersonal relations, performing one's social role;

5. Self-development - being aware of one's own individual characteristics, developing one's talents and other personal characteristics;

6. Achievements - regarding the task of solving certain life problems as a priority;

7. Spiritual satisfaction - being guided by moral principles, spiritual needs prevailing over material needs; 
8. Maintaining personal identity — one's own opinions, attitudes, and beliefs prevail over conventional ones; the uniqueness and independence of the self is preserved.

The five life spheres are: professional life, training and education, family life, social life and hobbies.

The Life Style Index questionnaire was developed in 1979 on the basis of R. Plutchik's psychoevolutionary theory and H. Kellerman's structural theory of personality. This method makes it possible to diagnose the system of ego defense mechanisms, to reveal the leading basic mechanisms, and to assess the degree of tension in each of them. The instrument comprises 92 questions, allowing us to define eight scales: denial, displacement, substitution, compensation, overcompensation, projection, and rationalization.

Eysenck's Self-Appraisals of Mental States Questionnaire allows evaluating the levels of the four emotional states: anxiety, frustration, aggressiveness, and rigidity. Test items consist of 40 statements. Respondents are asked to identify their own mental states by assigning to each statement a score -3 points if appropriate; 2 points if this condition is rare; 1 point if inappropriate.

The empirical data were analyzed using the following statistical methods:

- Evaluation of selected parameters of the distribution of a trait (mean values, variance, standard deviation) for a general description of the research results, evaluation of average norms, and the overall psychological portrait of the samples within the parameters laid down in the program of study;

- Student's t-test - to assess the differences in the mean values.-

We used the software package STATISTICA 12.0.

\section{Results}

Our findings show that in general, the teenagers who feel a low level of security or protection ("low-level-security teenagers") have a lower hardiness level compared to the "high-level-security teenagers".

The high level of hardiness for high-level-security teenagers prevents the occurrence of inner strain in stressful situations, due to the ability to firmly cope with stresses and perceive them as less significant. The hardiness of high-level-security teenagers invigorates them and motivates them towards self-realization, leadership, a healthy way of thinking and behaving. It gives them an opportunity to feel significant and valuable, to solve complex situations in reality despite the existence of stressors.

By comparing all the test metrics using Student's t-test, we found that the two groups of teenagers differ in their level of expressivity of each hardiness component, as well as in their hardiness level as a whole. These differences are significant (for all $p \leq 0.01$ ). The data obtained are given in Fig. 1 .

Comparative analysis reveals significant differences in the involvement between the groups $(t=-6.45, p \leq 0.01)$. The results indicate that the low-level-security teenagers possess a less developed involvement component compared to the highlevel-security teenagers, which makes them less capable of enjoying their activity. They feel rejected and "left out of life" more often. This feeling probably becomes 
fixed in their personality traits, making them more withdrawn. So, a vicious circle is formed, when the teenager's system of beliefs and personality traits generate a certain behavior which, in turn, promotes formation of relationships with people around him or her that will further solidify these beliefs.

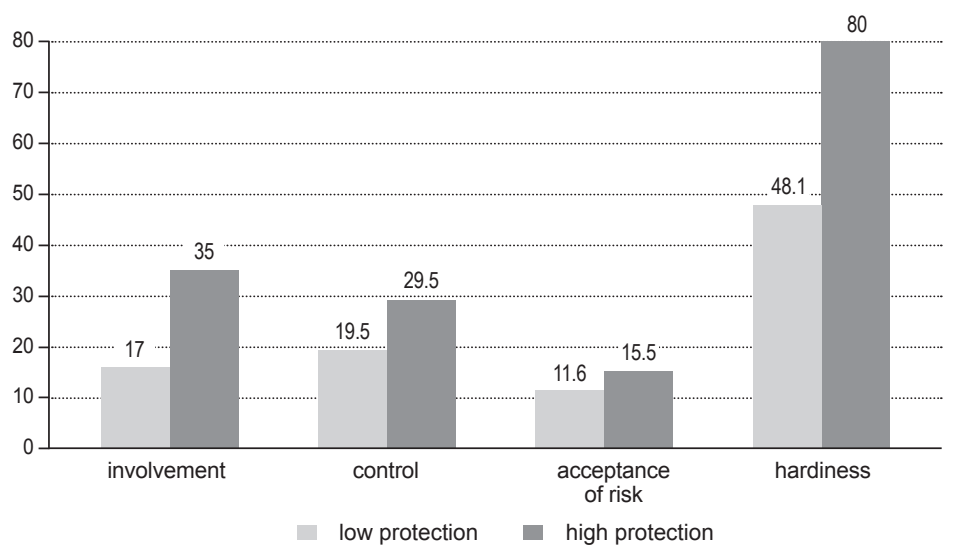

Figure 1. Expressivity of the average values of hardiness and its components in groups of teenagers with low and high security (protection) levels

The results of our experimental studies indicate that the low-level-security teenagers possess a less developed component of control $(t=-5.83, p \leq 0.01)$ compared to the high-level-security teenagers. This makes it possible to claim that high-levelsecurity teenagers have a stronger perception that they choose own their activities and their path, in comparison with low-level-security teenagers, who experience powerlessness, the impossibility to influence the results of what is going on, the futility of any effort.

Comparing the average expressivity of the control component in the groups mentioned above, it was found that the low-level-security teenagers possess a significantly lower level of control $(t=-4.24, p \leq 0.01)$. The data enable us to conclude that teenagers' firm conviction of the impossibility of influencing what is going on, typical of the low-level-security subjects, affects their behavior, minimizing their activity and attempts to change anything. Such people "forecast" failure, make fewer efforts, and, as a result, achieve less success. The absence of progress reinforces the conviction that all kinds of activity are useless. But the high-level-security teenagers are confident that they can influence a situation and treat it as less traumatic; they are more active in trying to change it, which leads to greater success. This attitude solidifies the appropriate belief system and motivates them to search for ways to influence the results of stressor-induced changes, as opposed to the state of helplessness and passivity typical of the polar group of subjects.

The study results prove that the low-level-security teenagers have a less developed component of risk-taking (described as the conviction that everything happening to a person promotes his or her development through knowledge gained by experience, whether positive or negative). The polar group of teenagers to a greater degree considers life as a way of gaining experience; they are ready to act without guaranteed success, at their own risk. They display self-confidence and determination when making choices in different reality situations. The high level of hardiness 
enables them to bear more easily the anxiety that accompanies any choice, opting in favor of uncertainty rather than certainty. This well-developed component of hardiness helps them remain open to the environment and society, to treat reality situations as tests and challenges. Quite the reverse, the low-level-security teenagers are anxious for assured results, comfort and safety; they find alien the idea of developing through gaining knowledge from experience and application of that knowledge.

Comparison of the study results obtained by using the Personal Differential technique detected differences in two statistically significant scales - the "estimation" scale $(t=5.32, p \leq 0.01)$ and the "activity" scale $(t=2.34, p \leq 0.05)$. It was established that the low-level-security teenagers possess lower self-esteem, and are more introverted than the high-level-security teenagers.

Comparison of the study results obtained by using the Self-Actualization Test is given in Fig. 2. Reliable differences were determined according to four statistically significant parameters. It turned out that the low-level-security teenagers possess lower indices: the "support" scale $(t=6.37, p \leq 0.01)$, the "value system" scale $(t=4.71, p \leq 0.05)$, the "self-esteem" scale $(t=5.61, p \leq 0.05)$, and the "self-acceptance" scale $(t=4.23, p \leq 0.05)$.

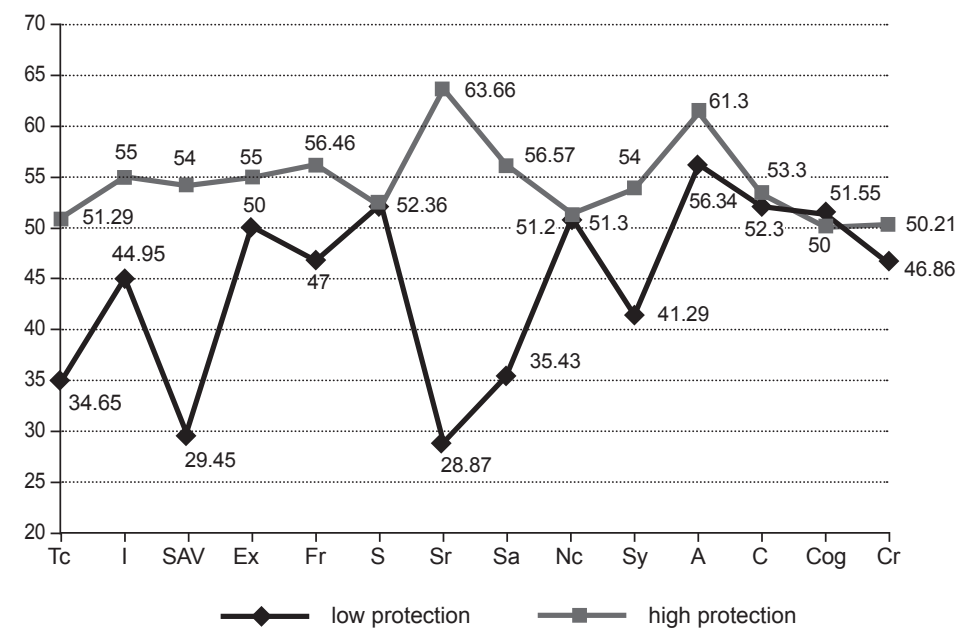

Figure 2. Results of the study of parameters according to the Self-Actualizing Test in groups of adolescents with low and high levels of security (protection)

Analysis of the results proves that the high-level-security teenagers possess a greater degree of independence in their actions, strive to follow their own goals, persuasions, and standards; typical for them is the ability to value their own advantages; they accept themselves the way they are. The higher the security indices, the higher the self-acceptance and self-esteem levels, and the better their capability for demonstrating independence in their actions, regardless of external factors.

Analysis of terminal values and overall life spheres established that the highlevel-security teenagers typically had a greater interest in self-development $(t=5.32$, $p \leq 0.05)$, as well as in achieving high results in the social sphere $(t=4.73, p \leq 0.05)$. Learning and education are more important to them than to the low-level-security teenagers $(t=-3.22, p \leq 0.05)$, while the low-level-security teenagers demonstrate 
significant concern about preserving their individuality compared to the high-level-security teenagers $(t=2.64, p \leq 0.05)$.

Significant differences were identified after comparing the results according to four parameters of psychological defense - projection, compensation, hypercompensation, and rationalization: Higher indices of defensive tension are typical for the low-level-security teenagers (Table 1). The high-level-security teenagers tend to use compensation $(t=-4.31, p \leq 0.01)$ and rationalization $(t=-5.12, p \leq 0.01)$ as defense mechanisms, whereas the low-level-security teenagers use projection $(t=6.64$ $p \leq 0.01)$ and hypercompensation $(t=3.74, p \leq 0.05)$. Thus, the low-level-security teenagers possess less constructive means of responding to stressful situations.

Table 1. Security intensity in groups of adolescents with low and high levels of protection (security) from violence in the educational environment

\begin{tabular}{lccc}
\hline Scale & $\begin{array}{c}\text { Average values in the } \\
\text { group with low level } \\
\text { of security }\end{array}$ & $\begin{array}{c}\text { Average values in the } \\
\text { group with high level } \\
\text { of security }\end{array}$ & $\begin{array}{c}\text { Reliability of differ- } \\
\text { ences (Student's } \\
\boldsymbol{t} \text { criterion) }\end{array}$ \\
\hline Exclusion & 27.3 & 24.4 & 2.74 \\
Regression & 27.61 & 25.3 & 2.36 \\
Substitution & 37.6 & 36.4 & 1.03 \\
Negation & 26.35 & 22.81 & 3.25 \\
Projection & 59.7 & 32.5 & $6.64^{* *}$ \\
Compensation & 29.82 & 38.13 & $-4.31^{* *}$ \\
Hypercompensation & 36.21 & 32.28 & $3.74^{*}$ \\
Rationalization & 21.3 & 42.2 & $-5.12^{* *}$ \\
\hline
\end{tabular}

* significance level $p \leq 0.05$; ${ }^{*}$ significance level $p \leq 0.01$.

Comparative analysis of the emotional states in both teenage groups shows that virtually all the indicators in the low-level-security group are higher. Reliable differences at a statistically significant level were discovered on the "anxiety" $(t=3.27$, $p \leq 0.05)$, "aggressiveness" $(t=6.73, p \leq 0.001)$, and "rigidity" $(t=6.84, p \leq 0.001)$ scales. We can state that the low-level-security teenagers are more anxious, aggressive, and rigid in the educational environment.

\section{Discussion}

To summarize, it can be stated that teenagers with a low level of psychological security from violence in the educational environment enjoy their own activity less than teenagers with a high level of psychological security. They more often have the feeling of being rejected or "left out of life". Teenagers with a high level of psychological security feel that they choose their own activities and their own way in life to a greater degree than do teenagers with a low level of psychological security, whereas the latter more frequently feel impotent, unable to influence what is happening around them, that their efforts are futile.

Teenagers with a low level of psychological security have a less developed component of risk taking, i.e., they are not convinced that everything that happens 
to them promotes their development due to the knowledge gained from their experience, both positive and negative. Teenagers with a high level of psychological security regard life as a way to gain experience to a greater degree. They are more frequently willing to risk acting in the absence of reliable guarantees of success. They show greater confidence and decisiveness while making their choice in various reality situations. The high hardiness level of teenagers who feel protected enables them to survive more easily the anxiety that follows a choice made in favor of uncertainty rather than certainty. Obviously, the phenomena of low and high security from psychological violence in the educational environment are closely connected with the person's hardiness.

Teenagers with a low level of psychological security have lower self-assessment; they are more introverted than teenagers with a high level of psychological security.

Teenagers with a high level of psychological security are characterized by a greater interest in their self-development, in achieving results in society. Learning and education are more significant for them, while teenagers with a low level of psychological security show a greater interest in maintaining their own individuality than do teenagers with a high level of psychological security. The results confirm that psychological violence affects teenagers' life goals and the reference points in their general view of the world. With decreasing psychological security come suspicion and egocentricity in the teenager's personality traits.

Analysis of the empirical characteristics established that teenagers with a high level of psychological security more often use compensation and explanation as defense mechanisms, whereas teenagers with a low level of psychological security resort to projection and hypercompensation. This means that teenagers with a low level of psychological security possess less constructive ways of responding to stressful situations. Teenagers with a low level of psychological security express their emotional state more strongly. They are more anxious, irritable, and aggressive, being less inclined to change their behavior, beliefs, and viewpoints.

Our research enables us to assert that the resources that provide the teenager's resistance to negative effects of psychological violence in the educational environment are the following:

- self-satisfaction, perception of oneself as a personality possessing positive and socially desirable characteristics;

- high self-control, a well-developed ability to stick to a chosen line of behavior regardless of the circumstances;

- openness and kindness, self-confidence;

- perception of the world as friendly and generous, which generates friendly behavior;

- holistic perception of the world, experiencing the present moment in its entirety, striving for self-development and self-perfection;

- independence of values and behavior from external factors;

- significance of such values as "achievement and self-development" and "high financial status", combined with a priority accorded to learning and education;

- explanation as a typical mechanism of psychological security, search for a reasonable basis for justification of behavior, activities, and impulsive acts;

- low level of anxiety, aggressiveness, and rigidity. 


\section{Conclusion}

Violence in the educational environment is becoming an ever more severe international problem, with its aspects widely discussed. All manifestations of violence must encounter resistance, as they destroy the values underlying democratic society (Forsman, 2006). The term used in international psychology research to describe violence against the individual personality in the educational environment is "bullying". Also used is the term "school violence", which describes abuse involving the use of force (coercion, including psychological coercion) by children among themselves, by teachers towards a student, and by students towards a teacher. Ordinary invisible but constantly repeated action violates the requirement of personality immunity and leads to suppression, oppression that affects well-being. If it is impossible to resist violence, it can cause "burnout" of the psychical activity. Children learn best of all in conditions under which they feel safe. Bullying devalues, isolates and scares people so much that they lose confidence in their own abilities. Every student has the right not to be exposed to violence or bullying during the whole day in the classroom and outside it. It is considered to be the responsibility of the whole school community to protect the child's right to have a feeling of safety at school (Fonagy, 2005).

To provide security from violence, it is vital to decrease it in the environment, which is an urgent social task. Integration and development of a person's inner resources to resist negative external influences are significant as well. This can be achieved with the help of psychological counseling and implemented in the educational environment, in order to translate the values of non-violence and security to the wider social context.

As shown by the empirical research, the necessity to counteract teenagers' manifestations of psychological violence in the school environment assumes that they possess certain psychological resources, which include hardiness as an integral personality education, which facilitates the overcoming of difficulties, and emotional, cognitive and behavioral sets represented by the relevant characteristics.

\section{References}

Alekseeva, L.S. (2006). Nasilie i psikhicheskoe zdorove detei [Violence and child mental health]. Semya $v$ Rossii [Family in Russia], 2, 73-80.

Alekseeva, I.A., \& Novoselskii, I.G. (2005). Zhestokoe obrashenie s rebenkom [Cruel treatment of children]. Moscow: Genezis.

Baeva, I.A. (2014). Psikhologicheskaya bezopastnost lichnosti: soprotivlyaemost cheloveka negativnyim vliyaniyam sotsialnoi sredy [Psychological safety of the personality: human resilience to negative influences of the social environment]. In I.A. Baeva \& S.V. Tarasov (Eds.), Bezopastnya obrazovatelnaya sreda: psikhologo-pedagogicheskie osnovyi formirovaniya, soprovozhdeniya $i$ otsenki [A safe educational environment: The psycho-pedagogical basis of forming, supporting and evaluation] (pp. 113-176). St. Petersburg, Russia: LOIRO.

Baeva, I.A. (2013). Resursy psikhologicheskoi zashishennosti i faktory soprotivlyaemosti nasiliu $\mathrm{v}$ ontogeneze [Resources of psychological protection and factors of resilience to violence in ontogenesis]. Izvestiya Rossiiskogo gosudarstvennogo pedagogicheskogo universiteta imeni A.I. Gertsena [Herzen University Journal of Humanities \& Sciences], 155, 5-16.

Baeva, I.A., \& Gayazova, L.A. (2015). Resursy bezopasnosti pozhilogo cheloveka, zashishayushie ot psikhologicheskogo nasiliya v blizhaishem sotsialnom okruzhenii [Resources for security 
of the elderly, protection from psychological violence in the immediate social environment]. In L.F. Obuchova (Ed.). Gorizonti zrelosti [Horizons of adulthood]. Moscow: MGPPU.

Baeva, I.A., Volkova, E. N., \& Laktionova, E.B. (2011). Psikhologicheskaya bezopastnost v obrazovatelnoi srede: razvitie lichnosti [Psychological security of the educational environment: the development of the personality]. Moscow - St. Petersburg: Nestor-Istoriya.

Burlachuk, L.F., \& Morozov, S.M. (2002). Slovar-spravochnik po psikhodiagnostike [Psychodiagnostics glossary]. St. Petersburg, Russia: Piter.

Davey, M., Eaker, D.G., \& Walters, L.H. (2003). Resilience processes in adolescents: Personality profiles, self-worth, and coping. Journal of Adolescent Research, 18(4), 347-362. doi: 10.1177/0743558403018004002

Dubrovina, I.V. (2000). Psikhicheskoe zdorovie detei i podrostkov $v$ kontekste psikhologicheskoi sluzhbi [The mental health of children and adolescents in psychological counseling services]. Ekaterinburg, Russia: Delovaya kniga.

Fonagy, P. (2005). Creating a peaceful school learning environment. University College London, England.

Forsman, A. (2006). The work against peer bullying. In Ahonen, A., Kurtakko, K. \& Sohlman, E. (Eds.), School, culture and well-being. Report in Educational Sciences, 4. Raveniemi: University of Lapland.

Karelin, A.A. (2007). Bolshaya entsiklopediya psikhologicheskich testov [Big encyclopedia of psychological tests]. Moscow: Eksmo.

Kobasa, S. C., Maddi, S. R., \& Kahn, S. (1982). Hardiness and health: A prospective study, Journal of Personality and Social Psychology, 42, 168-177. doi: 10.1037/0022-3514.42.1.168

Lam, C.B., \& McBride-Chang, C.A. (2007). Resilience in young adulthood: The moderating influences of gender-related personality traits and coping flexibility. Sex Roles, 56(3-4), 159-172. doi: 10.1007/s11199-006-9159-z

Leontiev, D.A. (2013). Test smyslozhiznennyikh orientatsyi [Test of meaningful life orientations]. Moscow: Smysl.

Luchshie psikhologicheskie testi (1992). [Best psychological tests]. Petrozavodsk: Kareliya.

Udin, N.V. (2009). Lichnostnyii resursy psikhologicheskoi zashishennosti studentov vuza v trudnykh zhiznennyh situatsiyakh [Personal resources for the psychological protection of university students in difficult situations], Izvestiya Rossiiskogo gosudarstvennogo pedagogicheskogo universiteta imeni A.I. Gertsena [Herzen University Journal of Humanities \& Sciences], 98, 17-32.

Volkova, E.N. (Ed.). (2011). Nasilie i zhestokoe obrashenie s detmi: istochniki, prichinyi, posledstviya, resheniya [Violence and abuse of children: sources, causes, effects, solutions]. St. Petersburg, Russia: Knizhnyii Dom.

Zinoveva, N.O., \& Mikhailova, N.F. (2003). Psikhologiya i psikhoterapiya nasiliya. Rebenok $v$ krizisnoi situatsii. [Psychology and psychotherapy of violence. The child in a crisis situation]. St. Petersburg, Russia: Rech.

Zinchenko, Yu.P., \& Zotova, O.Yu. (2010). Osnovaniya bezopasnosti cheloveka i obshestva [Foundations of the security of the individual and society]. Moscow: Publishing House of the Academy to Retrain and Improve the Qualifications of Educators.

Original manuscript received December 25, 2015 Revised manuscript accepted March 22, 2016 